\title{
Human Umbilical Cord Blood-derived Secretome Enhance Endothelial Progenitor Cells Migration on Hyperglycemic Conditions
}

\author{
Yudi Her Oktaviono*, Melly Susanti*
}

\section{Yudi Her Oktaviono*, Melly} Susanti

Department of Cardiology and Vascular Medicine, Faculty of Medicine, Universitas Airlangga, Prof Moestopo Street 6-8, Surabaya, INDONESIA.

\section{Correspondence}

\section{Yudi Her Oktaviono}

Department of Cardiology and Vascular Medicine, Faculty of Medicine, Universitas Airlangga, Prof Moestopo Street 6-8, Surabaya, INDONESIA.

E-mail: yoktaviono@gmail.com

History

- Submission Date: 02-04-2020;

- Review completed: 30-04-2020;

- Accepted Date: 19-05-2020.

DOI : 10.5530/pj.2020.12.

Article Available online http://www.phcogj.com/v11/i5

Copyright

(C) 2020 Phcogj.Com. This is an openaccess article distributed under the terms of the Creative Commons Attribution 4.0 International license.

\begin{abstract}
Hyperglycemia state is harmful to body's homeostasis. Uncontrolled hyperglycemic patients, especially patients with diabetes mellitus have a higher mortality risk of heart disease 2 to 4 times compared to non-hyperglycemic patients. Vascular endothelial impairment always been observed and found as a key feature of hyperglycemia state, which is correlated with reduced numbers and dysfunction of endothelial progenitor cells (EPCs). Objective: This paper aims to investigate the effect of hUCB-MSCs derived secretome treatment on the EPCs migration under hyperglycemia state. Material and Method: EPCs were isolated and cultured from peripheral blood samples and cultured for three days. Cultured EPCs were cultivated in 6-well plates until confluence and incubated with high glucose for 5 days, then placed in the modified Boyden chamber at the upper chamber with basal media. The lower chamber was supplemented with basal media and secretome at $2 \%, 10 \%$, and $20 \%$ concentration and VEGF treated group as a control. EPCS migration was evaluated using a Boyden chamber assay. Statistical analysis was performed using SPS 25.0. Results: EPCs migration were significantly higher when hUCB-MSCs-derived secretome was given in high glucose concentrations compared to the and control group (79.80 \pm 5.07 vs $51.00 \pm 5.15, p<0.000$ ). This study also showed that hUCB-MSCs-derived secretome increase EPCs migration under high glucose concentrations in a dose-dependent manner $(p<0.05)$. Conclusion: hUCB-MSCsderived secretome enhances EPCs migration under hyperglycemic state. This result may be of relevance for cell-free and regenerative therapeutic modality for a diabetic patient with coronary artery disease (CAD).
\end{abstract}

Key words: Mesenchymal stem cells, Endothelial progenitor cells, Secretome, Migration Hyperglycemia state.

\section{INTRODUCTION}

Cardiovascular disease, especially coronary heart disease has been always correlated with the longterm prognosis of patients with uncontrolled hyperglycemia, especially diabetes mellitus patients. Uncontrolled hyperglycemic patients have a higher mortality risk of heart disease ranging from 2 to 4 times higher compared to non-hyperglycemic patients. ${ }^{1} \quad$ Vascular endothelial impairment has been well observed and found as the main culprit of coronary heart disease in uncontrolled hyperglycemic patients. ${ }^{2-6}$ In uncontrolled hyperglycemic patients, endothelial dysfunction is caused by low levels and dysfunction of circulating endothelial progenitor cells (EPCs). Disruption of EPC function was found and observed in both of DM types, DM type $1^{3}$ and 2 . This finding proved that there is a correlation between uncontrolled hyperglycemia conditions and EPC dysfunction. ${ }^{4}$

After being recruited from the bone marrow, the circulating EPCs have the capability to differentiate into mature endothelial cells and also promote endothelial repair. It has been documented that EPCs plays major roles in both the stimulation of angiogenesis and vasculogenesis in human body. ${ }^{5}$ Hence, improvement in EPCs function may be very beneficial in reducing cardiovascular complications, especially coronary heart disease in uncontrolled hyperglycemic patients. ${ }^{6}$

Human mesenchymal stem cells (hMSCs) are multipotent stem cells that can be isolated from various tissue, such as bone marrow, adipose tissue, and postnatal tissue ${ }^{7}$ as used on this study is the human umbilical cord blood (hUCB-MSCs). The therapeutic effect of hMSCs is believed to originate from the soluble factors or cytokines known as secretome, which shown to increase neovascularization and angiogenesis. ${ }^{8-11}$ But its capability under hyperglycemia conditions has not yet been illustrated.

This study aims to investigate the migration capability of endothelial progenitor cells (EPCs) under hyperglycemia conditions, which is expected to mimic the metabolic disturbance that occurs in patients with type 2 diabetes mellitus.

\section{MATERIALS AND METHODS}

\section{Sample criteria}

This is an in-vitro study, with true experimental posttest only control group design. The blood sample was obtained from CAD patients in Dr. Soetomo General 
Hospital, Surabaya, Indonesia. The inclusion criteria were male, aged 40-59 years old, history of chronic ischemic heart disease as proven by coronary angiography results that showed $>50 \%$ stenosis of left main coronary artery or $>70 \%$ of other coronary arteries. The exclusion criteria were a history of the percutaneous coronary intervention procedure, coronary artery bypass grafting surgery, acute coronary syndromes, diabetes mellitus and anaemia. This study protocol has an ethical clearance from the Health Research Ethics Committee of Dr. Soetomo General Hospital, Surabaya (No.1567/KEPK/X/2019, approved on October $\left.8^{\text {th }}, 2019\right)$. The included subject has signed informed consent before subject recruitment.

\section{The hUCB-MSCs-derived secretome preparation}

Preparation of hUCB-MSCs-derived secretome was conducted as described in a previous study. ${ }^{12}$ HUCB-MSCs $(3 \mathrm{H}$ Biomedical $\mathrm{AB}$, Uppsala, Sweden) was cultured in Mesencult media (StemCell Technologies Inc., Vancouver, Canada) containing penicillin and streptomycin. Upon reaching $80 \%$ confluency, the media was replaced with supplement-free media and incubated for 24 hours. The media was collected and centrifuged. Supernatant was used as a conditioned medium contained with hUCB-MSCs-derived secretome.

\section{EPCs treatment}

Cultured EPCs were treated with high glucose and various concentrations of hUCB-MSCs-derived secretome (2\%,10\% and $20 \%)$. The control group was given VEGF $100 \mathrm{ng} / \mathrm{mL}$.

\section{EPCs isolation and culture}

EPCs were isolated from mononuclear cells (MNCs) of the peripheral blood of CAD patient. $40 \mathrm{ml}$ of blood was withdrawn and put into conical tubes and diluted with Phosphate buffer saline with $2 \%$ fetal bovine serum. Afterwards, Ficoll histopaque was added to the mixtures. And then centrifugation was done until peripheral blood MNCs layer was formed. And then $5 \times 105$ cells/mL PBMCs were cultured with basal Stemline II hematopoietic stem cell expansion medium (Sigma-Aldrich, St. Louis, MO, USA) supplemented with $15 \%$ fetal bovine serum and several growth factors in the fibronectin-coated 6-well plates. The culture was maintained at $37 \mathrm{C}$ with 5\% CO2 in a humidified atmosphere. Non-adherent cells were discarded, and fresh medium was added, after two days of culture. After three days of EPCs isolation and culture, EPCs were confirmed using FITC-labeled antihuman CD34 antibody (Biolegend, USA) staining and examined with immunofluorescence microscopy.

\section{Migration assay}

This experiment was performed using Costar ${ }^{\oplus}$ Transwell $^{\circledR}$ Permeable Support (Corning, USA) with a $3.0 \mu \mathrm{m}$ pore size membrane. EPCS migration was calculated using a Boyden chamber assay method. Isolated EPCs were detached using Trypsin EDTA solution (SigmaAldrich, USA). A total of $5 \times 105$ EPCs were incubated with high glucose ( $25 \mathrm{mmol} / \mathrm{L}$ D-Glucose, Sigma-Aldrich, USA). After 5 days, cells were placed in the modified Boyden chamber at the upper chamber with basal media. The lower chamber was supplemented with basal media and secretome at $2 \%, 10 \%$, and $20 \%$ concentration. The culture was incubated at $37^{\circ} \mathrm{C}$ for 24 hours. The non- migratory cells were removed manually. Meanwhile, the migratory EPCs below the upper chamber were fixed with $3.7 \%$ paraformaldehyde and permeabilized with methanol. Migrated EPCs were stained with Crystal Violet stain and calculated.

\section{Statistical analysis}

Statistical analyses were conducted using SPSS Statistics 24.0 from IBM to detect significance level at $\mathrm{p}<0.05$. Data were evaluated for normal distribution using the Kolmogorov Smirnov test and compared between groups using a one-way ANOVA test for migration and proliferation. Correlation between variables was obtained using Spearman correlation followed by a linear regression test.

\section{RESULTS}

\section{EPCs characteristics}

EPCs were successfully confirmed from peripheral blood MNCs, marked by positive CD34 on immunofluorescence. Light microscope view showed spindle-shaped cells which also characterize EPCs (Figure 1).

\section{Effect of hUCB-MSCs-derived Secretome on EPC migration}

hUCB-MSCs-derived secretome under non-glucose conditions induced a higher migration rate of EPC in a dose-dependent manner, but when compared to VEGF treated group, the migration was not significant.

\section{The hUCB-MSCs-derived Secretome improved EPCs migration under high glucose conditions}

As shown in Figure 2, EPCs migration was significantly higher treated with secretome of $20 \%$ concentrations under high glucose concentrations compared to VEGF treated EPCs $(79.80 \pm 5.07$ vs 51.00 $\pm 4.85, \mathrm{p}<0.000)$. EPCs migration was improved with a dose-dependent manner on the treatment with secretome alone and high glucose conditions. EPCs migration was significantly higher in secretome treated under high glucose concentrations groups compared to the secretome alone at $2 \%(40.40 \pm 4.72$ vs $17.20 \pm 1.92, \mathrm{p}<0.000), 10 \%$ $(56.00 \pm 5.34$ vs $27.00 \pm 4.00, \mathrm{p}<0.000)$, and $20 \%$ concentrations $(79.80$ \pm 5.07 vs $51.00 \pm 5.15, \mathrm{p}<0.000)$.

Treatment with secretome under high glucose concentrations group had a moderate correlation with EPCs migration $(\mathrm{r}=0.401 ; \mathrm{p}<0.000)$. The linear regression test showed an $r$-square of 0.638 . This suggested that the treatment with secretome under high glucose concentrations is responsible for $63.8 \%$ of EPCs migration.

\section{DISCUSSION}

In this study, we show that hUCB-MSCs-derived secretome has the capability of inducing the migration of EPC in a dose dependent manner under none and high glucose concentrations. Surprisingly, this effect statistically significant only with $20 \%$ concentrations of secretome and under high glucose concentrations, compared to VEGF treated group as a control.

The impaired migratory capacity of EPC in diabetic patients compared to healthy subjects has been well demonstrated in the previous study $^{3,13}$, it was also demonstrated the upregulated VEGF expression as a response of the low level of circulating EPCs. Unfortunately, the increased expression of VEGF was not followed by the improvement of EPCs number, thus therapeutic angiogenesis strategies by intensifying plasma VEGF may not be effective. ${ }^{13}$

The survival, migration, and angiogenesis capability of EPCs are known to be related by the expression and phosphorylation of endothelial nitric oxide synthase (eNOS). ${ }^{14-17}$ Nitric oxide derived from eNOS plays a major role in vascular integrity by upregulating VEGF expression. ${ }^{15}$ Hyperglycemia state was associated with inadequate production of eNOS activation, thus increasing the production of reactive oxygen species (ROS), which further impaired EPCs function. ${ }^{14-16}$ However, the pathophysiology behind the impairment of EPC in diabetic patients, have been described by Chen et al., which showed the reversal of EPC function after NO donor, not by antioxidants. ${ }^{14}$

Cytokine gradient has also been proposed as an essential mechanism behind the impairment of EPCs mobilization. ${ }^{8}$ The stromal cell-derived 

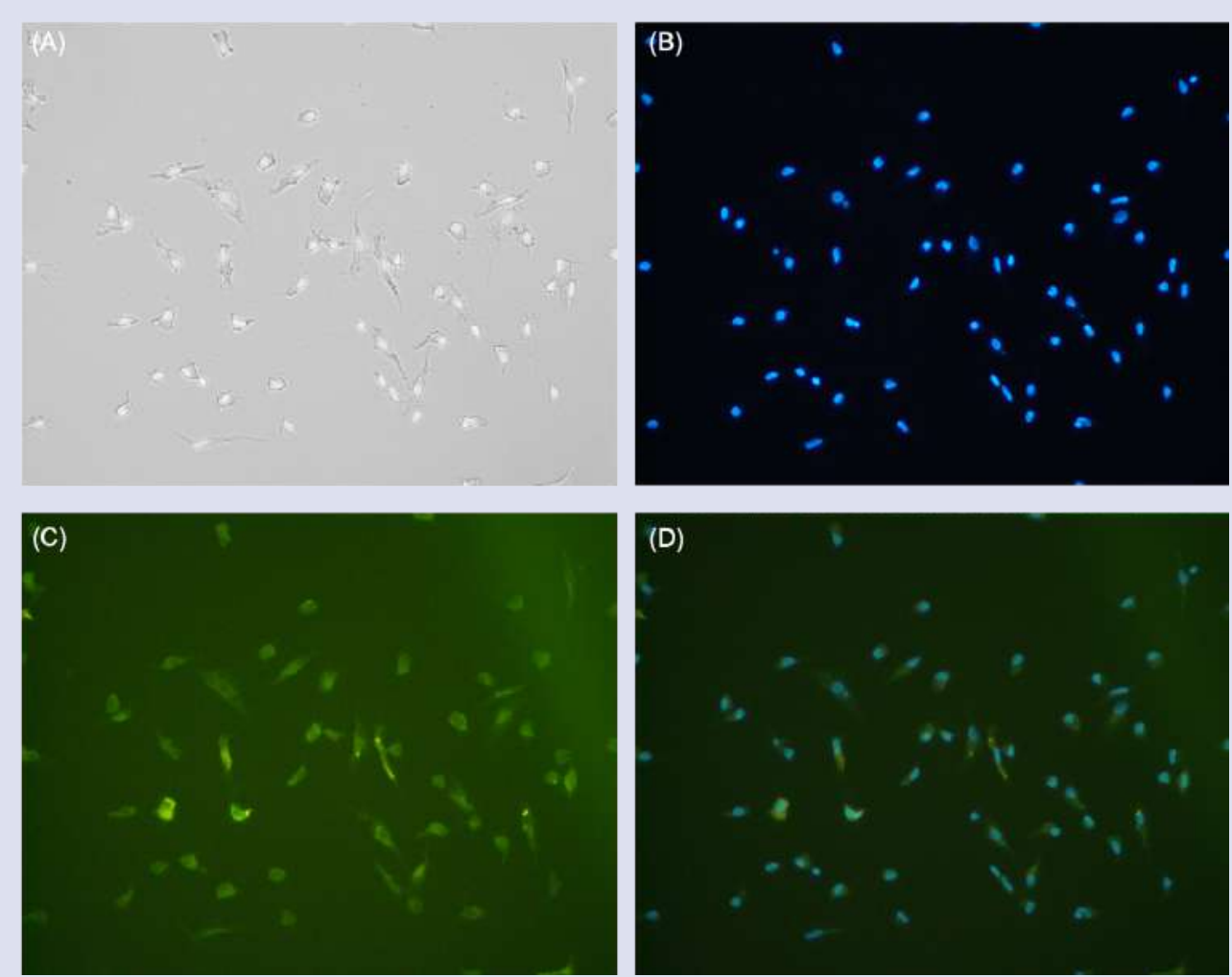

Figure 1: Microscopic finding of EPCs after three days incubation and culture (A) Light microscope view showing spindle shape of EPC (B) Blue fluorescent showing nuclear image of EPCs with diamidino-2phenylindole (DAPI) staining (C) Immumoflueresence view of EPCs stained with FITC-labelled anti-CD34 antibody (D) Merged view of $B$ and C.

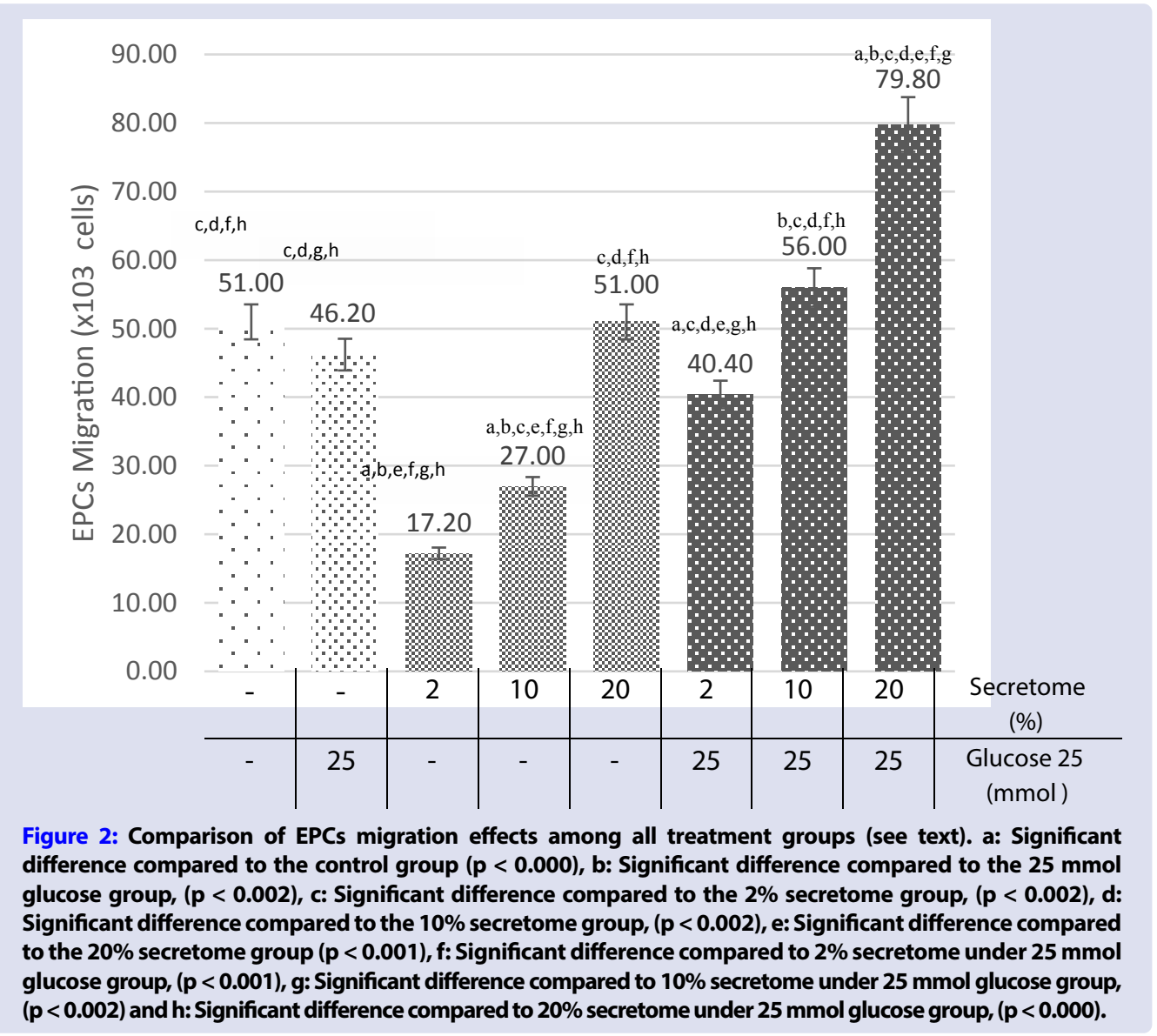


factor 1 (SDF-1 $\alpha$ ), through stimulation of its receptor (CXCR4) on the EPCs membrane, is a noteworthy chemokyne that responsible for the mobilization of EPC from bone marrow to ischemic tissues. ${ }^{8,15}$ Diabetes has been associated with the impaired production of SDF-1 $\alpha$ in the ischemic tissue. In contrast, production increased in bone marrow, which leads to a reduced chemoattractant gradient to mobilized EPCs from the bone marrow. ${ }^{15}$

Incorporating findings from previous studies, we hypothesize that improving the production of NO and increasing the concentration of chemoattractants, especially SDF-1 $\alpha$, may improve the EPCs migration capability.

The hUCB-MSCs exceptionally secrete higher amounts of important cytokines and growth factors, via either direct secretion or exosomes and microvesicles, compared to bone marrow derived MSCs. ${ }^{18}$ In terms of improving EPCs migration, secreted factors like G-CSF, GM-CSF SDF1, insulin-like growth factor 1 (IGF1), placental growth factor (PIGF), PDGF- $\beta,{ }^{8,18,19}$ and enhancing expression of iNOS through the secretion of extracellular vesicles, ${ }^{20}$ may play a major role in the mechanism of the hUCB-MSCs secretome capability.

\section{CONCLUSION}

In this study, we report for the first time, the paracrine effect associated with secreted factors from hUCB-MSCs, collectively known as secretome, have the capability of inducing EPCs migration under high glucose concentrations, thus may be of relevance for cell-free and regenerative therapeutic modality for a diabetic patient with CAD.

\section{REFERENCES}

1. Aronson, D. \& Edelman, E. R.: Coronary artery disease and diabetes mellitus. Cardiology Clinics 32, 439-55 (2014).

2. Saboor, M., Moinuddin, Ajmal, M. \& Ilyas, S.: Functional status of vascular endothelium in diabetes mellitus. J Ayub Med Coll Abbottabad 26, 239-43 (2014).

3. Tepper OM, Galiano RD, Capla JM, et al:: Human endothelial progenitor cells from type II diabetics exhibit impaired proliferation, adhesion, and incorporation into vascular structures. Circulation 106, 2781-6 (2002).

4. Brunner S, Schernthaner GH, Satler M, Elhenicky M, Hoellerl F, SchmidKubista KE, Zeiler F, Binder S, Schernthaner G.: Correlation of different circulating endothelial progenitor cells to stages of diabetic retinopathy: first in vivo data. Invest Ophthalmol Vis Sci 50, 392-8 (2009).

5. J. Wils, J. Favre, and J. Bellien.: Modulating putative endothelial progenitor cells for the treatment of endothelial dysfunction and cardiovascular complications in diabetes. Pharmacol Ther 170, 98-115 (2017).
6. Fadini GP, Sartore S, Albiero $M$ et al:: Number and function of endothelial progenitor cells as a marker of severity for diabetic vasculopathy. Arterioscler Thromb Vasc Biol, 26: 2140-46 (2006).

7. Jin HJ, Bae YK, Kim M, Kwon SJ, Jeon HB, Choi SJ, et al:: Comparative analysis of human mesenchymal stem cells from bone marrow, adipose tissue, and umbilical cord blood as sources of cell therapy. Int J Mol Sci 14 (9), 17986-18001 (2013)

8. Gallina C,Turinetto V,Giachino C.: A New Paradigm in Cardiac Regeneration: The Mes- enchymal Stem Cell Secretome. Stem Cells Int. 2015.

9. Konala VBR, Mamidi MK, Bhonde R, Das AK, Pochampally R, Pal R.: The current land- scape of the mesenchymal stromal cell secretome: A new paradigm for cell-free regenera- tion. Cytotherapy 18(1), 13-24 (2016).

10. Vizoso F, Eiro N, Cid S, Schneider J, Perez-Fernandez R.: Mesenchymal Stem Cell Secre- tome: Toward Cell-Free Therapeutic Strategies in Regenerative Medicine. Int J Mol Sci 18(9), 1852 (2017).

11. Phelps J,Sanati-Nezhad A,Ungrin M,Duncan NA,Sen A.: Bioprocessing of Mesenchymal Stem Cells and Their Derivatives: Toward Cell-Free Therapeutics. Stem Cells Int iii, 1-23 (2018).

12. Sandra F, Sudiono J, Sidharta EA, Sunata EP, Sungkono DJ, Dirgantara $Y$, et al.: Conditioned Media of Human Umbilical Cord Blood Mesenchymal Stem Cell-derived Secretome Induced Apoptosis and Inhibited Growth of HeLa Cells. Indonesia Biomed. J 6 (1), 57 (2014).

13. Chen, M. C., Sheu, J. J., Wang, P. W., Chen, C. Y., Kuo, M. C., Hsieh, C. J., Chen, J. F. \& Chang, H. W.: Complications impaired endothelial progenitor cell function in Type 2 diabetic patients with or without critical leg ischaemia: implication for impaired neovascularization in diabetes. Diabet Med 26, 134-41 (2009).

14. Chen YH, Lin SJ, Lin FY, Wu TC, Tsao CR, Huang PH et al:: High glucose impairs early and late endothelial progenitor cells by modifying nitric oxide-related but not oxidative stress-mediated mechanisms. Diabetes 56, 1559-68 (2007)

15. Yiu KH, Tse HF.: Specific role of impaired glucose metabolism and diabetes mellitus in endothelial progenitor cell characteristics and function. Arterioscler Thromb Vasc Biol 34(6), 1136-1143 (2014).

16. Fadini GP, Albiero M, Vigili de Kreutzenberg S, et al.: Diabetes impairs stem cell and proangiogenic cell mobilization in humans. Diabetes Care 36(4), 943-9 (2013).

17. Borniquel S, García-Quintáns N, Valle I, Olmos Y, Wild B, Martínez-Granero F, Soria E, Lamas S, Monsalve M.: Inactivation of Foxo3a and subsequent downregulation of PGC-1 alpha mediate nitric oxide-induced endothelial cell migration. Mol Cell Biol 30, 4035-44 (2010).

18. Arutyunyanl, Elchaninov A, Makarov A and Fatkhudinov T. Umbilical Cordas Prospective Source for Mesenchymal Stem Cell-Based Therapy. Stem Cells Int. (2016)

19. Kamprom W, Kheolamai $P$, U-Pratya $Y$, Supokawej A, Wattanapanitch $M$ Laowtam- mathron C and Issaragrisil S. Effects of Mesenchymal Stem CellDerived Cytokines on the Functional Eur. J. Cell Biol. (2016)

20. Tan CY, Lai RC, Wong W, Dan YY, Lim SK, Ho HK.: Mesenchymal stem cellderived exosomes promote hepatic regeneration in drug-induced liver injury models. Stem Cell Res Ther 5(3), 76 (2014). 


\section{GRAPHICAL ABSTRACT}

\section{ENDOTHELIAL PROGENITOR CELLS MIGRATION}

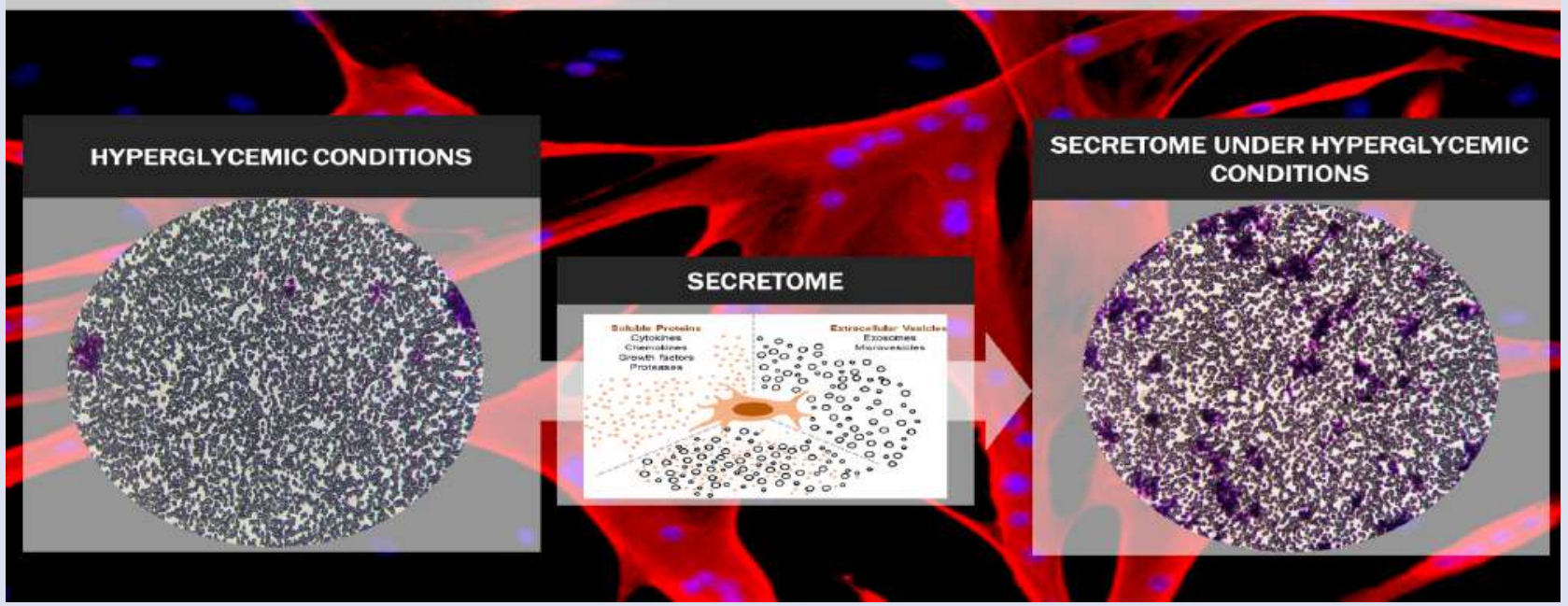

\section{ABOUT AUTHORS}

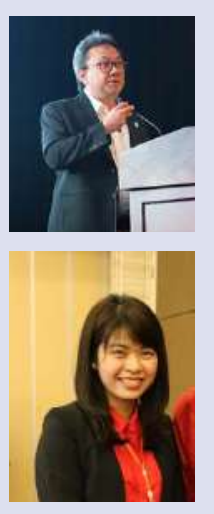

Yudi Her Oktaviono work as an interventional cardiologist in the Department of Cardiology and Vascular Medicine Soetomo General Hospital and Faculty of Medicine, University of Airlangga. Previously, He led the Indonesian Cardiologist association in Surabaya and currently he is the vice president of the Indonesian Cardiologist association. His research interests include complex interventional cardiology, endothelial progenitor stem cells, usage of natural compound for cardiac disease and detection of early cardiac markers.

Melly Susanti is a cardiology resident in the Department of Cardiology and Vascular Medicine Soetomo General Hospital and Faculty of Medicine, University of Airlangga. Her research interests are stem cells, genetic polymorphism of cardiovascular risk and clinical cardiology.

Cite this article: Oktaviono YH, Susanti M. Human Umbilical Cord Blood-derived Secretome Enhance Endothelial Progenitor Cells Migration on Hyperglycemic Conditions. Pharmacogn J. 2020;12(4):. 